\title{
Spatial and temporal characteristics of circumferential flow-function relations during acute myocardial ischemia in the conscious dog
}

\begin{abstract}
In the anesthetized open-chest dog the ischemic area produced by coronary occlusion is surrounded by an area of nonischemic contractile dysfunction, identified as the functional border zone. To establish whether a similar functional border zone exists in the conscious animal during acute regional ischemia and to determine its spatlal dimensions and temporal changes, we performed simultaneous two-dimensional echocardiography and radioactive microsphere studies in nine chronically instrumented dogs. We produced circumferential flow-function maps at 22.5-degree intervals over the full circumference of the left ventricle at the midpapillary muscle level during control conditions, 5 minutes after left circumflex occlusion, and -2.5 hours after left circumflex occlusion. After occlusion there was no change in left ventricular end-diastolic area, an increase in left ventricular end-systolic area $(p<0.01)$, and a decrease in left ventricular area ejection fraction $(p<0.01)$. The circumferential extent of left ventricular dysfunction was $197 \pm 11$ degrees (mean \pm .SEM) at 5 minutes of left circumflex occlusion, whereas the extent of subendocardial hypoperfusion was $144 \pm 6$ degrees $(p<0.0005)$. This produced a functional border zone measuring $54 \pm 8$ degrees, or $25 \%$ of the nonischemic myocardium, which did not change over the 2.5-hour occlusion period. Despite a modest but significant decrease in wall thickening (70 $\pm 6 \%$ to $43 \pm 6 \% ; p<0.01)$ in the functional border zone, there was no difference in subendocardial blood flow between the functional border zone and the control nonischemic area. We conclude that a discrete functional border zone exists in the conscious dog during acute regional ischemia produced by circumflex coronary occlusion, which does not change during the early evolution of myocardial infarction. The functional border zone likely contributes to minor overestimation of infarct size in the early hours after myocardial infarction if extent of, left ventricular dysfunction is used as an index of infarction in humans. (Am HEART J 1988;116:1514.)
\end{abstract}

Andrew J. Buda, Marshal Shlafer, and Kim P. Gallagher. Ann Arbor, Mich.

After acute coronary occlusion an area of severe myocardial dysfunction develops within seconds. ${ }^{1}$ Dyskinesis is apparent in the central ischemic zone, but depression of function extends beyond the ischemic boundaries to involve the adjacent nonischemic myocardium, and this has been termed the functional border zone. ${ }^{2-4}$ Although the size and characteristics of the functional border zone have been well characterized in the anesthetized open-

From the Cardiology Division, Department of Internal Medicine, and the Departments of Physiology, Surgery, and Pharmacology, University of Michigan Medical School.

Supported in part by a grant-in-aid from the American Heart Association of Michigan, Lathrup Village, Mich.; grants HL 29716, HL 34691, and HL 32043 from the National Heart, Lung, and Blood Institute, National Institutes of Health, Bethesda, Md; and National Institutes of Health Dicseari Cateer Development Award K04 HL04120 (Dr. Gallagher).

Received for publication June 6, 1988; accepted July 15, 1988.

Reprint requests: Andrew J. Buda, MD, Cardiology Division, TC-3910, 1500 E. Medical Center Dr., Ann Arbor, MI 48109-0366. chest animal,,$^{5-11}$ the conscious animal model is more analogous to the clinical situation, particularly for the study of acute coronary occlusion and myocardial infarction. ${ }^{12,13}$ The complicating effects of anesthesia, baroreflex depression, and the open-chest condition are avoided and, as a result, functional abnormalities are not influenced by these other variables. ${ }^{13,14}$ Furthermore, since there may be significant differences between the degree of ischemia, the time course of infarction, and subsequent functional alterations in the conscious animal, ${ }^{15}$ we designed our study to specifically study the spatial and temporal characteristics of the functional border zone during acute ischemia and infarction in the conscious canine model. Accordingly the specific goals of this study were: (1) to evaluate the circumferential extent of the functional border zone in the conscious dog during acute myocardial ischemia and (2) to assess any dynamic changes that occur in flow and function over the initial hours of ischemia and 


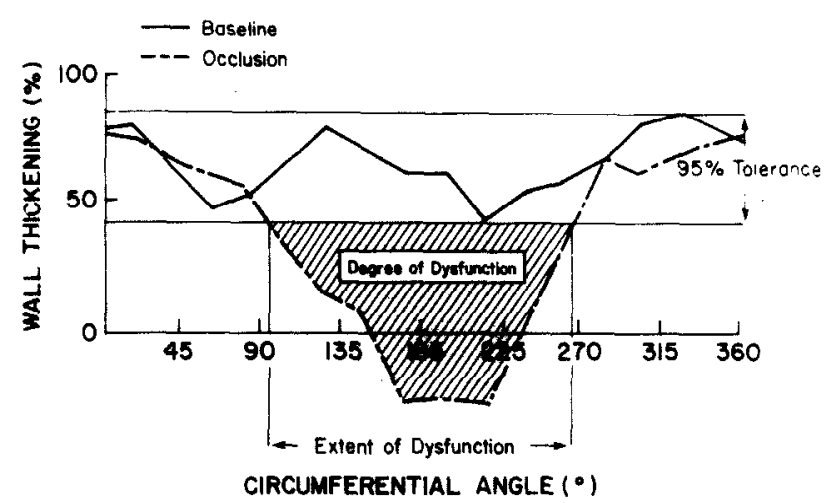

Fig. 1. Circumferential left ventricular function map at baseline and after coronary occlusion. Wall thickening data points were plotted at 22.5-degree intervals over the full 360 degrees. Extent of dysfunction is indicated as the circumferential measure of the map below $95 \%$ tolerance limit. Hatched area indicates degree of dysfunction.

infarction. Inasmuch as the results of this investigation in conscious closed-chest dogs have potentially greater clinical relevance than those obtained in open-chest dogs, our findings may prove useful in the interpretation of functional abnormalities associated with acute myocardial infarction in humans.

\section{METHODS}

Animal model. The study was performed in conditioned mongrel dogs of either sex, weighing between 18 and $27 \mathrm{~kg}$. Anesthesia was first induced with sodium thiamylal and then maintained with halothane. A sterile left-sided thoracotomy was performed through the fifth intercostal space. A Konigsberg (P7) high-fidelity micromanometer was introduced through the apex of the left ventricle to measure left ventricular pressure. A Tygon catheter (Norton Plastics, Akron; Ohio) was also introduced into the apex of the left ventricle for calibration of the Konigsberg manometer (Konigsberg Instruments, Inc., Pasadena, Calif.). A similar catheter was inserted into the left atrium for injection of microspheres. The proximal left circumflex artery was dissected free for placement of a hydraulic occluder, which was used to produce a coronary occlusion. Two small metallic markers were implanted in the subendocardium at the level of the papillary muscle to aid in spatial registration of subsequent two-dimensional echocardiographic studies. In some dogs a pulsed Doppler flow probe was placed proximal to the occluder on the circumflex artery to monitor coronary blood flow velocity. The signals from the flow probe were processed with a flowmeter constructed at the Dalton Research Center, University of Missouri (Columbia, Mo.).

The thoracotomy was closed after the catheters were brought subcutaneously to the back of the neck. All dogs were treated with antibiotics and given morphine sulfate ( 0.13 to $0.25 \mathrm{mg} / \mathrm{kg}$ intramuscularly) for postoperative

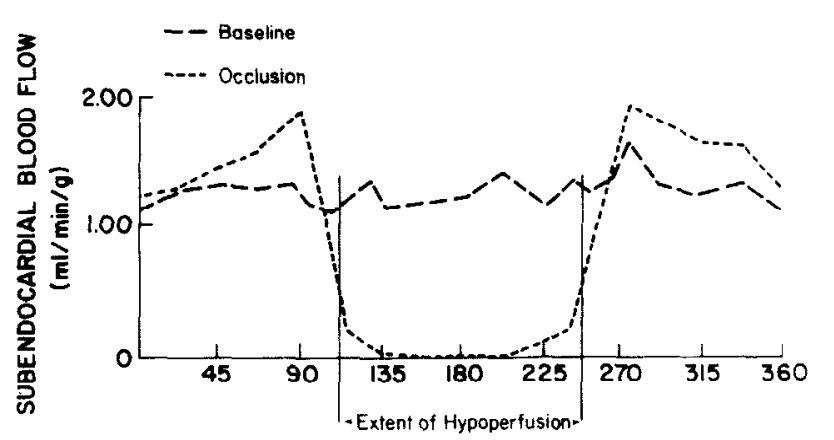

CIRCUMFERENTIAL ANGLE $\left({ }^{\circ}\right)$

Fig. 2. Circumferential left ventricular flow map at baseline and after coronary occlusion. Subendocardial blood flow data points were plotted at 22.5-degree intervals over the full 360 degrees. Extent of hypoperfusion is shown.

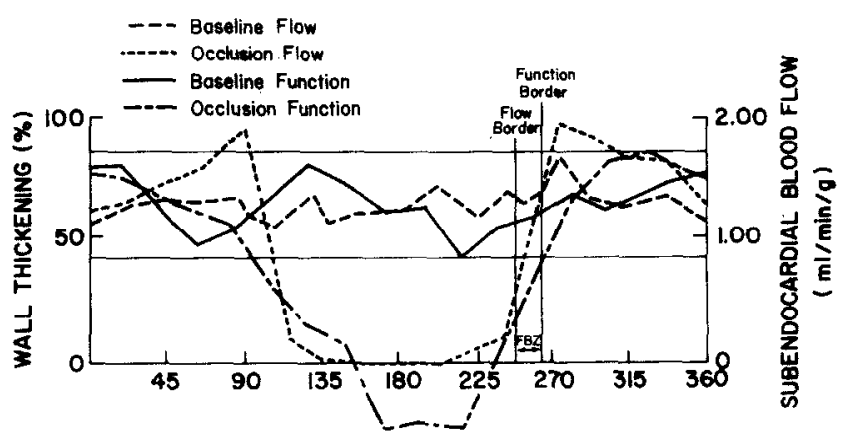

CIRCUMFERENTIAL ANGLE $\left({ }^{\circ}\right)$

Fig. 3. Circumferential flow and function maps (from Figs. 1 and 2) are superimposed and one lateral functional border zone $(F B Z)$ is illustrated. Data points correspond at 22.5-degree intervals.

analgesia. Studies were begun when the dogs were able to perform normal activities, approximately 10 to 14 days after surgery.

Experimental protocol. Animals were studied while lying down on their right sides on a table in the laboratory. Morphine sulfate $(0.5 \mathrm{mg} / \mathrm{kg}$ intramuscularly) was given for analgesia approximatcly 15 minutes before the beginning of the experiment. Additional morphine sulfate $(0.13$ $\mathrm{mg} / \mathrm{kg}$ ) was administered during the occlusion period if the dogs showed signs of discomfort or pain. A femoral cutdown was performed under local anesthesia for insertion of an arterial catheter used to measure arterial blood pressure and to withdraw a reference blood sample for calculating myocardial blood flow.

Nine animals were used in this study. Heart rate, arterial pressure, left ventricular pressure, and $\mathrm{dp} / \mathrm{dt}$ were measured continuously throughout the study. Tracerlabeled microspheres ( $15 \mu \mathrm{m}$ diameter) were injected into the left atrium for determination of regional myocardial blood flow by means of the reference withdrawal method. ${ }^{16}$ 


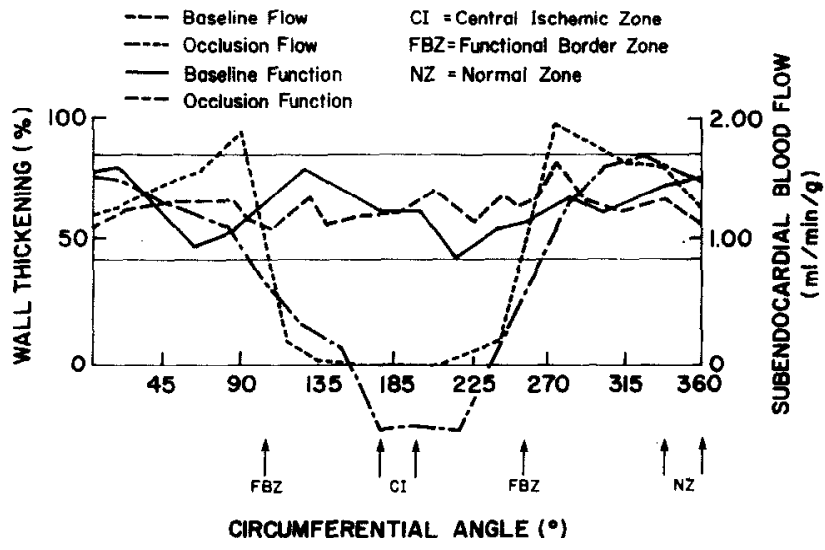

Fig. 4. Circumferential flow and function maps are superimposed and specific zones for data analysis are indicated.

The isotopes $\left({ }^{141} \mathrm{Ce},{ }^{51} \mathrm{Cr},{ }^{113} \mathrm{Sn},{ }^{103} \mathrm{Ru},{ }^{95} \mathrm{Nb},{ }^{46} \mathrm{Sc}\right)$ used for each study varied depending on the availability of the isotope at the time. The microspheres, suspended in $10 \%$ dextran with $0.01 \%$ Tween-80, were ultrasonicated and vortex agitated before injection. One to two million microspheres were injected each time over a 15- to 20-second period. A previous study in our laboratories has demonstrated that this number of microspheres is sufficient for accurate determinations of blood flow and delineation of the ischemic-nonischemic interface. ${ }^{7}$ The reference arterial blood sample was withdrawn at a rate of $7 \mathrm{ml} / \mathrm{min}$ with a Harvard withdrawal pump starting 10 seconds before injection and continuing for 120 seconds after completion of injection. Microspheres were injected before occlusion of the circumflex coronary artery, 10 minutes after occlusion, and 2.5 hours after occlusion.

Two-dimensional echocardiography was performed with a Diasonics $3400 \mathrm{R}$ scanner and a $2.5 \mathrm{MHz}$ transducer. Images were recorded on a videocassette recorder for future analysis. The two-dimensional echocardiography transducer was placed on the closed, shaved, right side of the chest, which served as a standoff to allow full visualization of the circumferential extent of the left ventricle in the short-axis projection. The left ventricle was scanned from the aortic valve to the apex and the midpapillary muscle position was identified. Two-dimensional echocardiographic studies were performed at the same time as microsphere injections. Care was taken to make all recordings during periods of normal sinus rhythm. Occlusion lasted for a period of 3 hours. At the completion of the study the animals were anesthetized with sodium pentobarbitol; they were then killed by potassium chloride injection and the hearts were excised. The left ventricle was dissected from the surrounding tissue and placed in formalin to facilitate subsequent sectioning.

Frhnnardisaraphic arialysis. With the use of a minicomputer-based video digitizing system, two-dimensional echocardiographic analysis was performed as previously described. ${ }^{5,17}$ In brief, end-diastolic and end-systolic
Table I. Hemodynamic data

\begin{tabular}{cccc}
\hline Data & Baseline & $\begin{array}{c}\text { Occlusion } \\
(5 \mathrm{~min})\end{array}$ & $\begin{array}{c}\text { Occlusion } \\
(2.5 \mathrm{hr})\end{array}$ \\
\hline $\begin{array}{c}\text { Heart rate } \\
\text { (beats/min) }\end{array}$ & $85 \pm 5$ & $134 \pm 7^{*}$ & $108 \pm 8 \dagger . \pm$ \\
$\begin{array}{c}\text { Mean arterial } \\
\text { pressure (mm Hg) }\end{array}$ & $105 \pm 4$ & $111 \pm 5$ & $108 \pm 3$ \\
$\begin{array}{c}\text { Left ventricular } \\
\text { systolic pressure } \\
\text { (mm Hg) }\end{array}$ & $140 \pm 6$ & $138 \pm 7$ & $139 \pm 5$ \\
$\begin{array}{c}\text { Left ventricular } \\
\text { end-diastolic } \\
\text { pressure (mm Hg) }\end{array}$ & $11.9 \pm 1.5$ & $17.2 \pm 2.1^{*}$ & $17.9 \pm 2.3 \dagger$ \\
$\begin{array}{c}\text { Peak positive dp/dt } \\
\quad(\mathrm{mm} \mathrm{Hg} / \mathrm{sec})\end{array}$ & $3708 \pm 151$ & $3444 \pm 194$ & $3249 \pm 198 \dagger$ \\
$\begin{array}{c}\text { Peak negative dp/dt } \\
(\mathrm{mm} \mathrm{Hg} / \mathrm{sec})\end{array}$ & $2762 \pm 307$ & $2494 \pm 212$ & $2614 \pm 275$ \\
\hline
\end{tabular}

${ }^{*} p<0.003$ vs baseline.

$+p<0.02$ vs baseline.

$\ddagger p<0.02$ vs occlusion ( $5 \mathrm{~min}$ ).

frames were selected for analysis. The onset of the $\mathrm{Q}$ wave in lead II defined end diastole, and the smallest ventricular cavity defined end systole. Endocardial and epicardial borders were carefully traced directly from the video display by means of a digitizing tablet. All two-dimensional echocardiographic measurements were then reported as the mean of three consecutive heartbeats. Our laboratory has previously validated our two-dimensional echocardiographic measurements by means of a specially constructed phantom and in the intact heart. ${ }^{18,19}$

Quantitative analysis was performed by means of a radial contraction model and a fixed diastolic center of mass at 22.5-degree intervals over the full 360-degree circumference. For correction of rotation the midpoint of the posterior papillary muscle was fixed at 135 degrees. Wall thickening was calculated as: end-systolic wall thickness - end-diastolic wall thickness/end-diastolic wall thickness $\times 100 \%$. Area ejection fraction was calculated as: left ventricular end-diastolic area - end-systolic area/ end-diastolic area $\times 100 \%$. 'The mean \pm stanadard deviation wall thickening was calculated for three normal beats, and $95 \%$ tolerance limits for normal were established in each animal. Functional maps were drawn for each animal. Functional abnormality was expressed as the circumferential extent (in degrees) and the degree of dysfunction (in square centimeters). These parameters were measured directly from each occlusion function map. The extent of dysfunction was defined as the circumferential distance between the curve intercepts where the occlusion curve went below the lower normal tolerance limit; the degree of dysfunction was measured as the area of the map, determined by planimetry, that went below the lower tolerance limit (Fig. 1).

Regional blood flow maps. Transverse rings of the left ventricle ( 15 to $18 \mathrm{~mm}$ in width) corresponding to the level of the echocardiographic images were used for determination of blood flow. The cross-sectional rings were dissected 
Table II. Left ventricular global function

\begin{tabular}{cccc}
\hline & Baseline & $\begin{array}{c}\text { Occlusion } \\
(5 \mathrm{~min})\end{array}$ & $\begin{array}{c}\text { Occlusion } \\
(2.5 \mathrm{hr})\end{array}$ \\
\hline $\begin{array}{c}\text { I.eft ventricular } \\
\text { end-diastolic } \\
\text { area }\left(\mathrm{cm}^{2}\right)\end{array}$ & $14.8+0.8$ & $15.9+0.9$ & $16.8 \pm 1.0^{*}$ \\
$\begin{array}{c}\text { Left ventricular } \\
\text { end-systolic } \\
\text { end-systolic } \\
\text { area (cm }\end{array}$ & $5.1 \pm 0.5$ & $9.2 \pm 0.9 \dagger$ & $9.5 \pm 0.9 \dagger$ \\
$\begin{array}{c}\text { Left ventricular } \\
\text { area ejection } \\
\text { fraction }(\%)\end{array}$ & $66.1 \pm 2.1$ & $43.0 \pm 2.8 \dagger$ & $44.2 \pm 2.2 \dagger$ \\
\hline
\end{tabular}

${ }^{*} p<0.05$ vs baseline.

tp $<0.01$ vs baseline.

into sixteen 22.5-degree full-thickness sectors corresponding to those of the two-dimensional echocardiographic study. The sections near the edge of the ischemic area were divided into two full-thickness sections to improve delineation of the perfusion boundary. Each section of tissue was further divided into equal thirds from the endocardium to the epicardium. The tissue samples were then weighed and placed in counting vials for assay of radioactivity in a Tracor (model 1185) gamma scintillation counter (Tracor Northern Inc., Middleton, Wis.). After the counts in each tissue sample were corrected for background and overlapping counts with simultaneous equations, blood flow was calculated with the equation: $Q_{m}=\left(C_{m} \times Q_{r}\right) / C_{r}$, where $Q_{m}=$ myocardial blood flow $(\mathrm{ml} / \mathrm{min}), C_{m}=$ counts $/ \mathrm{min}$ in tissue samples, $Q_{r}=$ withdrawal rate of the reference arterial sample $(\mathrm{ml} / \mathrm{min})$, and $\mathrm{C}_{\mathrm{r}}=$ counts/min in the reference arterial sample. Flow per gram of tissue was calculated by dividing flow by the weight of the appropriate sample. Background and overlap corrections and blood flow calculations were performed on an Apple II+ microcomputer. Circumferential blood flow maps were generated by means of a computer-assisted program. ${ }^{5,7}$ Hypoperfusion was defined as a $50 \%$ decrease in subendocardial blood flow, ${ }^{20}$ and the extent of hypoperfusion was measured in degrees (Fig. 2).

Data analysis. The circumferential wall thickening maps were superimposed on the subendocardial perfusion maps to compare the extent of dysfunction with the extent of hypoperfusion ${ }^{5}$ In some animals geometric distortion related to fixation produced spatial registration irregularities at the lateral borders of the flow-function maps. In these instances the maps were superimposed by matching the centers of the hypoperfusion and dysfunctional zones and generating the maps laterally from these centers. In all animals the functional border zone was defined as the absolute difference (measured in degrees and millimeters) between the circumferential extent of dysfunction and the circumferential extent of hypoperfusion (Fig. 3). In addition, three regions consisting of two sectors each were identified on each regional functional and flow map for statistical comparison of wall thickening and subendocar-
Table III. Left ventricular wall thickening

\begin{tabular}{lccc}
\hline & Baseline & $\begin{array}{c}\text { Occlusion } \\
(5 \mathrm{~min})\end{array}$ & $\begin{array}{c}\text { Occlusion } \\
(2.5 \mathrm{hr})\end{array}$ \\
\hline $\begin{array}{c}\text { Central ischemic } \\
\text { zone }\end{array}$ & $67.7 \pm 3.6 \%$ & $-0.5 \pm 3.6 \%$ & $1.2 \pm 3.8 \% *$ \\
$\begin{array}{c}\text { Functional } \\
\text { border zone }\end{array}$ & $70.4 \pm 5.7 \%$ & $43.2 \pm 5.6 \% *$ & $40.7 \pm 3.7 \%^{*}$ \\
Normal zone & $80.6 \pm 6.8 \%$ & $71.9 \pm 4.2 \%$ & $72.5 \pm 7.2 \%$ \\
\hline
\end{tabular}

${ }^{*} p<0.01$ vs baseline.

dial blood flow during control and ischemic conditions (Fig. 4). The central ischemic region was defined as two consecutive sectors contained completely within the ischemic area. The border zone region was defined as one of two sectors immediately adjacent to the ischemic area. The normal region was defined as two consecutive sectors remote from the ischemic area. The slope of left ventricular dysfunction was calculated for each lateral functional border. The region in the area 0 to 50 degrees corresponded to the septal border, whereas the region in the area of 150 to 200 degrees was the free wall border. Each slope was measured by performing linear regression analysis on the function points from the central ischemic zone to the normal myocardium on each lateral border.

Statistical analysis. All values are expressed as mean \pm standard error. Analysis of variance was used to analyze differences within groups across conditions. When a significant effect was seen, paired $t$ tests were used to discriminate which conditions differed from one another. Bonferroni correction of the acceptable $p$ level was used. ${ }^{31}$

\section{RESULTS}

Hemodynamic parameters. The dogs weighed $24.5 \pm 0.9 \mathrm{~kg}$. Hemodynamic data are summarized in Table I. Heart rate increased significantly from baseline to occlusion $(p<0.003)$. Although heart rate dropped by the end of the occlusion period, it was still significantly increased above baseline $(p<0.02)$. There was no change in mean arterial pressure or left ventricular systolic pressure with occlusion. Left ventricular end-diastolic pressure increased significantly with occlusion $(p<0.003)$ and remained elevated at the end of the 2.5 hours $(p<0.02)$. Late in occlusion there was a significant drop in peak positive $\mathrm{dp} / \mathrm{dt}(p<0.02)$. There were no changes in peak negative $\mathrm{dp} / \mathrm{dt}$ over the course of the study.

Global left ventricular function. Changes in left ventricular function are outlined in Table II. After occlusion there was no initial change in the left ventricular end-diastolic area measured by twodimensional-echocardiography $\left(14.8 \pm 0.8 \mathrm{~cm}^{2}\right.$ at baseline vs $15.9 \pm 0.9 \mathrm{~cm}^{2}$ at early occlusion; $p=\mathrm{NS}$ ). However, left ventricular end-diastolic 


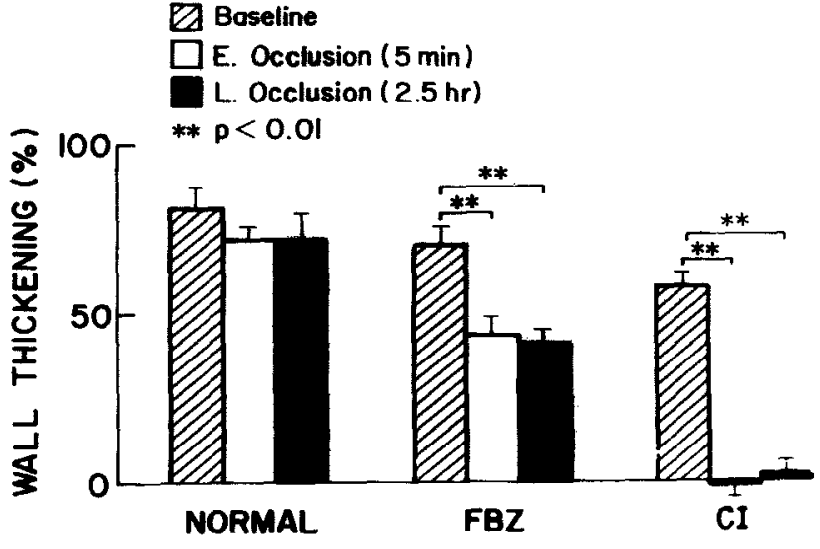

Fig. 5. Wall thickening data at baseline, after early $(E)$ occlusion, and after late $(L)$ occlusion are shown for different myocardial zones. $C I$, central ischemic zone; $F B Z$, functional border zone.

area was significantly increased at late occlusion $(p<0.05)$. Left ventricular end-systolic area increased early after occlusion from $5.1 \pm 0.5 \mathrm{~cm}^{2}$ to $9.2 \pm 0.9 \mathrm{~cm}^{2}(p<0.01)$ and remained increased 2.5 hours later $\left(9.5 \pm 0.9 \mathrm{~cm}^{2}\right)$. Left ventricular area ejection fraction was $66.1 \pm 2.1 \%$ at baseline and decreased to $43.0 \pm 2.8 \%$ with occlusion $(p<0.01)$. Area ejection fraction was not reduced further 2.5 hours after occlusion $(44.2 \pm 2.2 \%)$.

Regional left ventricular function. Left ventricular dysfunction, as determined by two-dimensional echocardiography, was visually apparent immediately after occlusion in all animals. Percentages of wall thickening in the normal zone, the functional border zone, and the central ischemic zone are summarized in Table III and Fig. 5. In the central ischemic zone wall thickening was replaced by thinning $(-0.5 \pm 3.6 \% ; p<0.01)$ at early occlusion. There was minimal improvement at the end of the occlusion period, but this change was not statistically significant. In the normal zone wall thickening was unaffected by the ischemic insult. However, in the functional border zone there was significant dysfunction after occlusion $(p<0.01)$, and no improvement was noted 2.5 hours later. The extent of the wall thickening abnormality was $197.4 \pm 11.0$ degrees at early occlusion and remained unchanged (183.5 \pm 8.6 degrees, $p=$ NS) at late occlusion. The degree of dysfunction remained the same throughout occlusion $\left(46.6 \pm 3.9 \mathrm{~cm}^{2}\right.$ at early occlusion vs $39.9 \pm 5.2 \mathrm{~cm}^{2}$ at late occlusion; $p=\mathrm{NS}$ ).

Differences in the absolute slope of dysfunction measured directly from the circumferential left ventricular function maps are shown in Fig. 6. After coronary occlusion the septal wall slope of dysfunc-

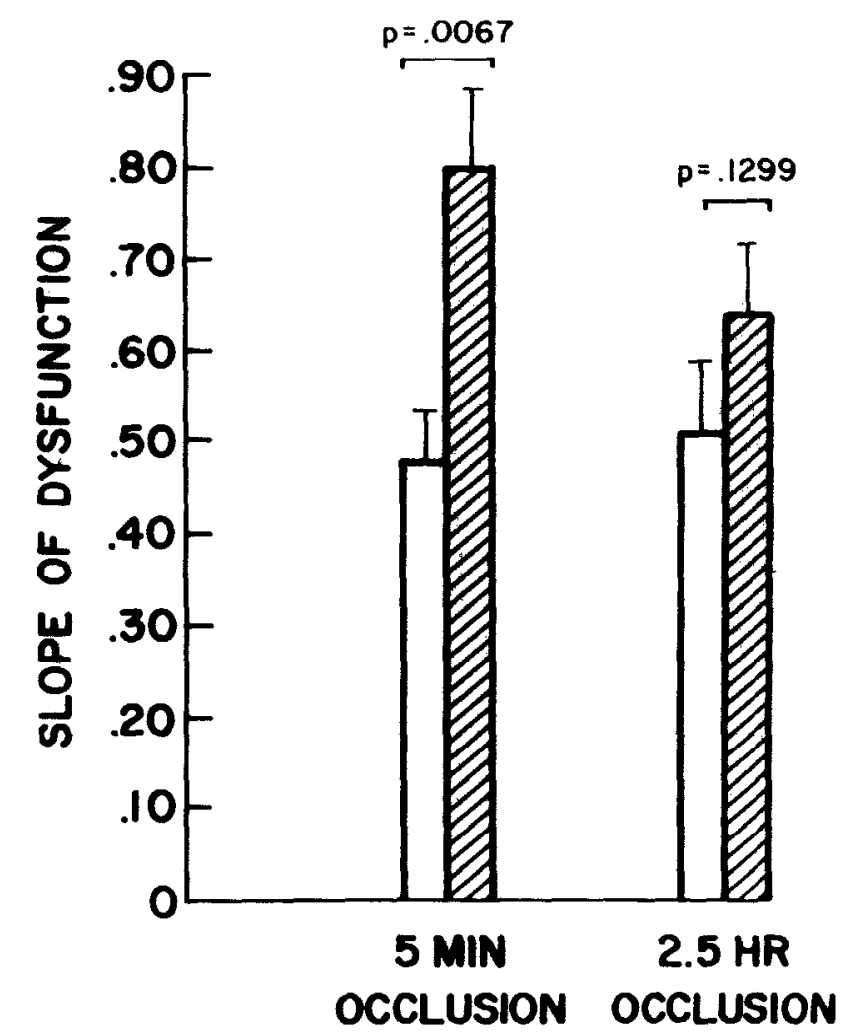

Fig. 6. Slope of dysfunction for septal and left ventricular free wall is illustrated after 5 minutes of occlusion and at 2.5 hours of occlusion. Note slope of dysfunction of septal wall is significantly less than that of free wall at 5 minutes of occlusion. Difference is no longer apparent at 2.5 hours of occlusion.

tion was less $(p=0.0067)$ than the free wall slope of dysfunction. However, by 2.5 hours of occlusion this difference in slopes of dysfunction was no longer apparent.

Myocardial blood flow. The myocardial blood flow data are summarized in Table IV and Fig. 7. Baseline blood flows were comparable in all zones. After coronary occlusion blood flow in the central ischemic area decreased markedly. In the functional border zone there was no significant change in myocardial blood flow either at 5 minutes or 2.5 hours after occlusion compared to baseline values. In the normal nonischemic zone, blood flows increased immediately after coronary occlusion but were similar to baseline values by 2.5 hours after coronary occlusion. In addition, it is important to note that blood flows in the functional border zone were similar to those in the normal nonischemic 
Table IV. Myocardial blood flows (ml/min/gm)

\begin{tabular}{cccc}
\hline Zone & Baseline & $\begin{array}{c}\text { Occlusion } \\
(5 \mathrm{~min})\end{array}$ & $\begin{array}{c}\text { Occlusion } \\
(2.5 \mathrm{hr})\end{array}$ \\
\hline $\begin{array}{l}\text { Central ischemic zone } \\
\text { Subendocardial }\end{array}$ & $0.97 \pm 0.10$ & $0.05 \pm 0.02^{*}$ & $0.11 \pm 0.03^{*}$ \\
$\begin{array}{l}\text { Subepicardial } \\
\text { Functional border zone }\end{array}$ & $0.79 \pm 0.09$ & $0.30 \pm 0.10^{*}$ & $0.44 \pm 0.11 \dagger$ \\
$\begin{array}{l}\text { Subendocardial } \\
\text { Subepicardial }\end{array}$ & $1.08 \pm 0.13$ & $1.33 \pm 0.18$ & $1.12 \pm 0.12$ \\
Normal zone & $0.97 \pm 0.14$ & $1.16 \pm 0.23$ & $1.16 \pm 0.21$ \\
Subendocardial & $1.02 \pm 0.12$ & $1.34 \pm 0.18 \dagger$ & $1.19 \pm 0.14$ \\
Subepicardial & $0.75 \pm 0.07$ & $1.08 \pm 0.10^{*}$ & $0.93 \pm 0.09$ \\
\hline
\end{tabular}

${ }^{*} p<0.01$ vs baseline.

$t p<0.05$ vs baseline.

area, both at 5 minutes and 2.5 hours after coronary occlusion (Table IV). The extent of hypoperfusion in the subendocardium measured $144 \pm 6$ degrees at 5 minutes after occlusion and was similar $(139 \pm 4$ degrees) at 2.5 hours.

Circumferential flow-function relations. The circumferential extent of left ventricular dysfunction was consistently greater than the extent of subendocardial hypoperfusion (197.4 \pm 11.0 degrees vs $143.6 \pm$ 6.4 degrees at early occlusion and $183.5 \pm 8.6$ degrees vs $138.9 \pm 5.4$ degrees at late occlusion; $p<0.0005$ for both comparisons). The functional border zone therefore measured $54 \pm 8$ degrees (or approximately $9 \mathrm{~mm}$ on either lateral border) at early occlusion and $45 \pm 11$ degrees (or approximately $8 \mathrm{~mm}$ ) at late occlusion (Fig. 8). The change from early to late occlusion was not statistically significant.

\section{DISCUSSION}

Our results in these studies, performed with conscious closed-chest dogs, indicate that a zone of dysfunction measuring approximately 50 degrees surrounds the ischemic area produced by circumflex coronary artery occlusion. This corresponds remarkably closely to results of our previous studies performed in anesthetized open-chest dogs, ${ }^{5,7}$ suggesting that neither anesthesia nor the conscious state significantly alters circumferential flow-function relations after sudden severe myocardial ischemia. Indeed the similarities in these studies support the concept that severe myocardial ischemia is the most important factor in producing the tethering effect that constrains the lateral zones of the ischemic bed. ${ }^{2-11}$

There were marked hemodynamic and loading differences between results of our previous studies in the anesthetized dogs and those of the present studies in the conscious dogs. Of note, the heart rate

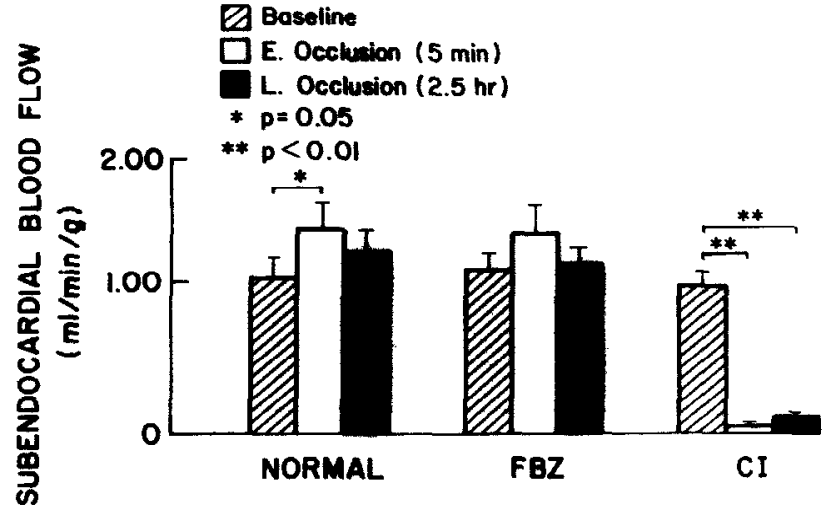

Fig. 7. Subendocardial blood flow data at baseline, after early $(E)$ occlusion, and after late $(L)$ occlusion are shown for different myocardial zones. $C I$, central ischemic zone; $F B Z$, functional border zone.

increased after coronary occlusion $(58 \% ; p<0.003)$ in the conscious animals, whereas there was little change $(-3 \% ; p=N S)$ in the anesthetized dogs. There was a marked increase in the left ventricular end-diastolic area in the anesthetized group ( $+24 \%$; $p<0.01$ ) with little change in the conscious group $(+7 \% ; p=N S)$. The fact that we observed similar circumferential flow-function results despite markedly different hemodynamic and loading conditions between the anesthetized and the conscious groups further underscores the fact that the functional border zone is relatively fixed after a severe ischemic insult.

It is also interesting to note that the degree of wall thickening abnormality in the functional border zone was modest in the conscious animals (absolute change $=-39 \%$ ) compared to the anesthetized dogs (absolute change $=-56 \%$ ). This most likely relates to the fact that reflex changes in remote nonischemic myocardium are consistently greater in the conscious animals than in the anesthetized animals. This reflex increase in remote nonischemic thickening may have affected function in the region of the functional border zone as we have recently demonstrated after inotropic intervention. ${ }^{22}$ This would explain the fact that the relative functional impairment produced by a tethering effect was minimized in the conscious compared to the anesthetized state despite similar degrees of ischemia as evidenced by reductions in subendocardial blood flow.

Our results concerning determination of the functional border zone by means of two-dimensional echocardiography closely agree with those of Gallagher et al., ${ }^{23}$ who used sonomicrometer techniques in the conscious dog model. In the latter study sigmoid curves to wall thickening data were fitted after circumflex coronary occlusion to model the 


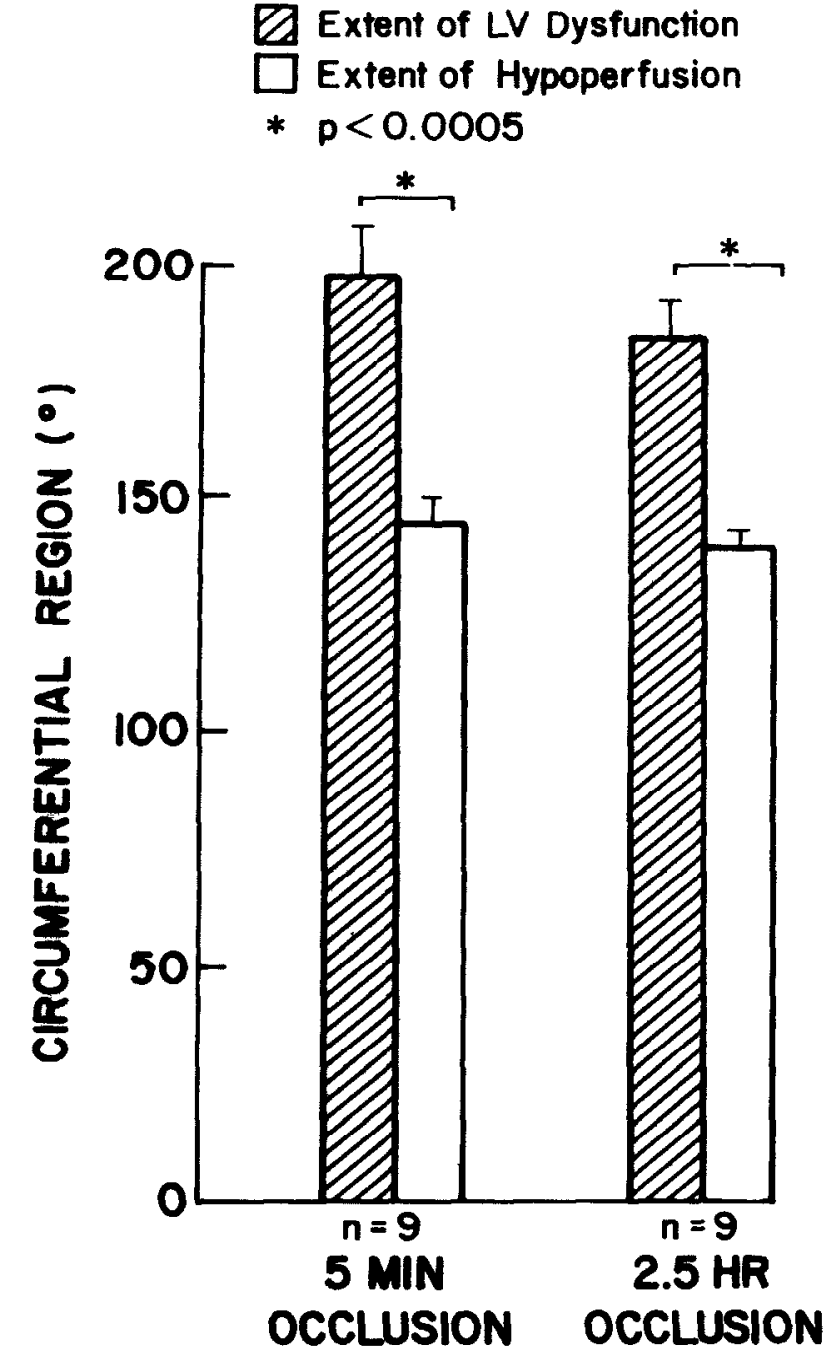

Fig. 8. Extent of left ventricular dysfunction and hypoperfusion is illustrated. Difference between these two extents represents the functional border zone. Note the extent of dysfunction and hypoperfusion does not change between 5 minutes and 2.5 hours. Thus, there is no change in the functional border zone.

distribution of regional contractile impairment as a function of distance from the perfusion boundary. The lateral extent of one functional border zone in this study was approximately 30 degrees (or 60 degrees on both lateral borders), which agrees well with the present study. Furthermore, in accordance with our present findings, the average severity of nonischemic dysfunction within the functional border zone was mild. The fact that these studies which used sonomicrometry, and the present study, which used two-dimensional echocardiography, vield similar results despite differences in measurement techniques and methods of analysis further emphasizes the fixed and discrete relationship of the functional border zone to the central ischemic area in the conscious animal.

The circumferential flow-function relations remained fixed over the 2.5-hour duration of coronary occlusion. Inasmuch as myocardial necrosis is known to begin approximately 20 to 40 minutes after coronary occlusion, ${ }^{24}$ it is clear that the evolution of infarction did not alter the initial ischemic circumferential flow-function relationships. Neither the extent of the functional border zone nor the degree of functional impairment by wall thickening measurement changed during this time frame. Although infarct size was not directly determined for the purpose of this study, our results support the fact that myocardial necrosis does not alter flowfunction relations during the early phase of infarction. This is in agreement with results of recent studies from our laboratory ${ }^{5,25}$ and others, ${ }^{26}$ which have examined serial functional changes over the first few hours of coronary occlusion. These experiments have shown that the functional abnormalities determined within minutes of coronary occlusion are well demarcated and do not change over the next 6 hours. However, in these previous investigations myocardial blood flow was not measured so that dynamic changes in myocardial perfusion could not be eliminated as a complicating factor in the interpretation of the functional results. Our data extend the findings of these earlier experiments by providing evidence that perfusion abnormalities, as well as regional dysfunction, do not change over the first few hours of myocardial ischemia and infarction.

The asymetry of the slope of transition of regional ventricular function from ischemic to nonischemic regions has been previously noted by us in the anesthetized animal model. ${ }^{22}$ The septal wall had a significantly less steep slope of transition compared to the lateral wall, suggesting that the septum may exert a different level of tethering or constraining effect on normal myocardium that does not occur in the regions of the lateral free wall. However, the fact that there was an initial difference in the slope of transition between the septal wall and the free wall after coronary occlusion, which subsequently resolved at 2.5 hours of occlusion, suggests that some form of global left ventricular remodeling may be occurring during the early infarct period. This remodeling did not influence the circumferential flow-function relations but may be an important mechanism in subsequent shape changes that occur after infarction, as is most severely evident in the case of infarct expansion. Serial studies over a 
period of days will be necessary to elucidate the potential effect of remodeling on myocardial function or infarct expansion.

The possible mechanisms responsible for the functional border zone have been addressed in several previous reports. ${ }^{5-11,27-29}$ We believe that the most likely explanation is that localized increases in regional left ventricular wall stress occur at the lateral borders of the myocardium as proposed by Bogen et al. ${ }^{28,}{ }^{29}$ Computations for their theoretical model of the infarcted left ventricle were based on finite element solutions yielding end-diastolic and end-systolic pressure-volume curves from which ventricular function curves were calculated for infarcts of varying sizes and material properties. By means of the theoretical model they predicted that circumferential stress was increased in the 49- to 60-degree zone immediately adjacent to the infarct area in close agreement with our present and previous findings. ${ }^{5,7}$ The level of stress amplification in this zone was found to be independent of infarcts between $15 \%$ and $40 \%$ in size but diminished with increasing stiffness. However, the precise pathophysiologic mechanisms related to dysfunction in the border area remain to be elucidated.

There are certain methodologic concerns that should be noted in our study. Although both internal landmarks and implanted metallic markers were used to carefully identify and reference the "slice" of myocardium used for both functional measures by two-dimensional echocardiography and coronary flow measures by radioactive microspheres, we cannot exclude the possibility of registration error in constructing our circumferential flow-function maps. It would require a minimum of three markers to clearly identify a specific tomographic plane. And even with precise identification of the sector plane there is no simple way of correcting for the change in tomographic plane that occurs because of threedimensional translational motion of the heart between diastole and systole. The registration difficulties could have been compounded by shrinkage artifacts that occur after fixation of the heart before dissection for gamma counting of samples for blood flow measurements. However, we should point out that great care was used to precisely match internal landmarks of the heart, such as the papillary muscles, and to correct for rotational error. Furthermore, in the case of obvious misregistration of flow and function data, the flow and function maps were constructed laterally from the midpoints of the subendocardial blood flow abnormality and the region of dyskinesis. This phase correction shift of flow-function would then correct this error but would make measurement of absolute functional border zones at one lateral border impossible. As a result the total functional border zone was measured, and a single lateral dimension was estimated as approximately one half of the total abnormality. In addition, we should acknowledge the fact that our flow-function maps are constructed from discrete data points at 22.5-degree intervals. In this sense our data are not continuous but approach the limits of spatial resolution of the techniques that we used. Finally we should comment on our definition of hypoperfusion zone, which was based on an arbitrary $50 \%$ decrease in subendocardial blood flow as suggested by previous investigators. ${ }^{20}$ It should be noted, however, that blood flow decreases abruptly at both lateral ischemic borders, and thus a change in blood flow threshold for hypoperfusion is unlikely to significantly alter the width of our functional border zones. Despite these unavoidable limitations of our methodology, we believe that any errors in measurements are minimal and are unlikely to have affected our results.

Our method of analysis may have influenced our results since we have measured specific zones directly from our circumferential flow-function maps, whereas others ${ }^{9,10}$ have used specific categorical data. This may partly explain some of the apparent discrepancies and controversies related to the size of the functional border zone. However, we should emphasize the fact that our results achieved by means of our specific methods of analysis agree closely with those achieved with sonomicrometry techniques. ${ }^{7}$ There is also a growing consensus among investigators that this functional border zone is relatively discrete..$^{5-8,11,23}$

Our data have important clinical implications that deserve comment. Given that the conscious dog is a better model of the clinical situation than the anesthetized animal, ${ }^{12}$ our results can be extrapolated cautiously to acute myocardial ischemia and infarction in humans. It is important to emphasize that the functional abnormality produced after occlusion occurred immediately and was unchanged over the initial few hours after infarction. Thus any significant change in regional function in the ischemic area after acute coronary occlusions should correspond to a change in regional perfusion or a change in the intensity of ischemia. For example, in the setting of thrombolytic therapy or other acute intervention, regional function may improve as myocardial perfusion is restored. However, this response may be masked by the well-described stunning of 
myocardial function, ${ }^{30,31}$ at least for several hours or days after the initial ischemic insult.

Another clinical implication relates to the use of the circumferential extent of the functional abnormality as an index of the size of the acute ischemic area at risk. Although results of our previous studies, the present investigation, and other reports all indicate that the functional abnormality overestimates the size of the ischemic area, there is now a consensus ${ }^{5-8,11,23}$ that this overestimation measures approximately 50 degrees in total extent (or 8 to 9 $\mathrm{mm}$ on each lateral border) after proximal circumflex occlusion. Thus the size of the ischemic area at risk could be estimated by subtracting this sum from the total functional abnormality. It should be emphasized, however, that this provides only an estimate of the area at risk and not of infarct size, since the rate or progression of evolution of infarction is not reliably reflected by acute changes in functional parameters. Changes in the extent of the functionally defined area at risk may prove useful for evaluation of different interventions. We emphasize, however, that subtantial additional research is necessary to explore these possibilities, especially in light of recent preliminary evidence that the size of the functional border zone may vary by location in the left ventricle. ${ }^{32}$

In conclusion, our data demonstrate that a functional border zone measuring approximately 50 degrees exists in the conscious animal after occlusion of the circumflex coronary artery. The flowfunction relations that are established immediately after coronary artery occlusion do not change over the first 2 to 3 hours in the evolutionary phase of infarction. These data suggest that functional parameters are useful in estimating the size of the myocardial area at risk in the early hours after acute circumflex coronary occlusion.

We acknowledge the excellent technical assistance of Diane $P$. Pace, BS, and Lisa C. Krause, MA, in these studies. We thank Ms. JoEllen Mahs for excellent secretarial support.

\section{REFERENCES}

1. Tennant R, Wiggers CJ. The effect of coronary occlusion on myocardial contraction. Am J Physiol 1935;112:351.

2. Cox DA, Vatner SF. Myocardial function in areas of heterogeneous perfusion after coronary occlusion in conscious dogs. Circulation 1982;66:1154.

3. Kerber RE, Marcus ML, Ehrhardt J, Wilson R, Abboud FM. Correlation between echocardiographically demonstrated segmental dyskinesis and regional myocardial perfusion. Circulation 1975;52:1097.

1 Wrent+ UI, Mcorbaum S, Heni MK, Rit J, Gueret P, Corday E. Experimental evaluation of the extent of myocardial dysenergy and infarct size by two-dimensional echocardiography. Circulation 1981;63:607.
5. Buda AJ, Zotz RJ, Gallagher KP. Characterization of the functional border zone using circumferential regional flowfunction maps. J Am Coll Cardiol 1986;8:150.

6. Force T, Kemper AJ, Perkins L, Gilfoil M, Cohen C, Parisi AF. Overestimation of infarct size by quantitative twodimensional echocardiography: the role of tethering and of analytic procedures. Circulation 1986;73:1360.

7. Gallagher KP, Gerren RA, Stirling MC, Choy M, Dysko RC, McManimon SP, Dunham WR. The distribution of functional impairment across the lateral border of acutely ischemic myocardium. Circ Res 1986;58:570.

8. Guth BD, White FC, Gallagher KP, Bloor CM. Decreased wall thickening in myocardium adjacent to ischemic zones in conscious swine during brief coronary artery occlusion. AM HEART J 1984;107:458.

9. Homans DC, Aisinger R, Elsperger KJ, Erlier D, Sublett E, Mikell F, Bache RJ. Regional function and perfusion at the lateral border of ischemic myocardium. Circulation 1985; 71:1038.

10. Lima JAC, Becker LC, Milin JA, Kallman CH, Weisfeldt ML, Weiss JL. Impaired thickening of nonischemic myocardium during acute regional ischemia in the dog. Circulation 1985;71:1048.

11. Sakai KK, Watanabe K, Millard RW. Defining the mechanical border zone: a study in the pig heart. Am J Physiol 1985;249 (Heart Circ Physiol 18):H88.

12. Reimer KA, Jennings RB, Cobb FR, Murdock RH, Greenfield Jr JC, Becker LC, Bulkley BH, Hutchins GM, Schwartz RP, Bailey KR, Passamani ER. Animal models for protecting ischemic myocardium: results of the NHLBI cooperative study. Comparison of unconscious and conscious dog models. Circ Res 1985;56:651.

13. Vatner SF, Braunwald E. Cardiovascular control mechanisms in the conscious state. N Fingl J Med 1975;293:970.

14. Van Citters RL, Franklin PL, Rushmer RF. Left ventricular dynamics in dogs during anesthesia with alpha-chloralose and sodium pentobarbital. Am J Cardiol 1964;13:349.

15. Jugdutt BI, Riesel M, Henriksen J, Wortman C. Different relations between infarct size and occluded bed size in barbiturate-anesthetized versus conscious dogs. J Am Coll Cardiol 1985;6:1035.

16. Heymann MA, Payne BD, Hoffman JIE, Rudolph AM. Blood flow measurements with radionuclide-labeled particles. Prog Cardiovasc 1977;20:55.

17. Buda AJ, Zotz RJ, Pace DP, Krause IC, Turla M. Immediate rebound followed by deterioration of regional left ventricular function with coronary reperfusion. J Am Coll Cardiol 1986; 8:333.

18. Weiss RJ, Buda AJ, Pasyk S, O'Neill WW, Keyes Jr JW, and Pitt B. Noninvasive quantification of jeopardized myocardial mass using two-dimensional echocardiography and thallium201 tomography. Am J Cardiol 1983;52:1340.

19. Zotz RJ, Meyer CR, Delp EJ, Bookstein FL, Buda AJ. Reliability of measurements from two-dimensional echocardiographic images using a cardiac phantom [Abstract]. Clin Res 1985;33:240A

20. Murdock RH, Harlan Jr DM, Morris III JJ, Pryor Jr WW, Cobb FR. Transitional blood flow zones between ischemic and nonischemic myocardium in the awake dog. Analysis based on distribution of the intramural vasculature. Circ Res 1983;52:451.

21. Morrison DF. Multivariate statistical analysis. New York: McGraw-Hill Book Company, Inc, 1967:113-48.

22. Buda AJ, Zotz RJ, Gallagher KP. The effect of inotropic stimulation on normal and ischemic myocardium following coronary occlusion. Circulation 1987;76:163.

23. Gallagher KP, Gerren RA, Ning X, McManimon SP, Stirling MC, Shlafer M, Buda AJ. The functional border zone in conscious dogs. Circulation 1987;76:163.

24. Reimer KA, Jennings RB. The wavefront phenomenon of myocardial ischemic cell death. II. Transmural progression of 
necrosis within the framework of ischemic bed size (myocardium at risk) and collateral flow. Lab Invest 1979;40:633.

25. Buda AJ, Zotz RJ. Serial assessment of circumferential regional left ventricular function following complete coronary occlusion. AM HEarT J 1986;112:447.

26. Gillam LD, Franklin TD, Foale RA, Wiske PS, Guyer DE, Hogan RD, Weyman AE. The natural history of regional wall motion in the acutely infarcted canine ventricle. J Am Coll Cardiol 1986;7:1325.

27. Tyberg JV, Parmley WW, Sonnenblick EH. In vitro studies of myocardial asynchrony and regional hypoxia. Circ Res 1969;25:569.

28. Bogen DK, Needleman A, McMahon TA. An analysis of myocardial infarction. The effect of regional changes in contractility. Circ Res 1984;55:805.
29. Bogen DK, Rabinowitz SA, Needleman A, McMahon TA, Abelmann WH. An analysis of the mechanical disadvantage of myocardial infarction in the canine left ventricle. Circ Res 1986;47:728.

30. Heyndrickx GR, Millard RW, McRitchie RJ, Maroko PR, Vatner SF. Regional myocardial functional and electrophysiological alterations after brief coronary artery occlusion in conscious dogs. J Clin Invest 1975;56:978.

31. Braunwald F, Kloner RA. The stunned myocardium: prolonged, postischemic ventricular dysfunction. Circulation 1982;66:1146.

32. Marino PN, Becker LC, Lima JAC, Weiss JL. Greater dysfunction of non-ischemic myocardium during acute anterior vs inferior transmural ischemia [Abstract]. $J$ Am Coll Cardiol 1986;9:92A.

\section{Effects of residual stenosis on infarct size and} regional transmural myocardial blood flow after reperfusion

This study in dogs was designed to determine the effects of residual stenosis on infarct size and on the transmural distribution of coronary flow in the central and peripheral ischemic perfusion bed. A plastic shunt containing a Doppler flow probe was inserted between the left anterior descending coronary artery and the subclavian artery. The dogs were divided into two groups. Group $1(N=7)$ underwent total shunt occlusion for 2 hours followed by reperfusion at $50 \%$ of control flow for 2 hours. Group $2(N=8)$ underwent 2 hours of total occluslon followed by 2 hours of total reperfusion. Regional blood flow was measured by radiolabeled microspheres, and infarct areas were quantitated with triphenyl tetrazolium chloride staining. Infarct sizes expressed as a percentage of the left ventricle or as a percentage of perfusion territory were significantly $(\rho<0.05)$ smaller in animals with total repefusion (group 2$)$ than in dogs with partial reperfusion (group 1). Endocardial flows in the central infarct zone were significantily higher in dogs with totel reperfusion than was observed with partial reperfusion; epicardial flows were not significantly different. In the peripheral region both endocardial flows and epicardlal nows with total reperfusion were significantly higher than with partial reperfusion. These studies suggest that residual stenosis after thrombolysis may increase infarct size and reduce endocardial flow in the central infarct zone and transmural flow in the peripheral zone. (AM HEART J 1988;116:1523.)

Jack L. Wilson, PhD, K. B. Ramanathan, MD, Leslie A. Ingram, MS, and David M. Mirvis, MD. Memphis, Tenn.

From the Department of Anatomy and Neurobiology, and the Department of Medicine, University of Tennessee, and the Medical Service, Veterans Administration Medical Center.

Supported by research grants from the National Heart, Lung, and Blood Institute (HL20597), Bethesda, Md., and the Veterans Administration, Washington, $\mathrm{D}$. C.

Received for publication Jan. 19, 1988; accepted July 15, 1988.

Reprint requests David M. Mirvis, MD, 956 Court Ave, Room F208, Memphis, TN 38163.
Thrombolytic therapy permits rapid reperfusion of ischemic myocardium in patients with acute myocardial infarction. ${ }^{1}$ Factors that determine whether or not the restoration of flow produces structural and functional recovery include the size of the ischemic perfusion bed, ${ }^{2}$ the collateral blood flow, ${ }^{3}$ the duration of coronary occlusion before reperfusion, ${ }^{4}$ and myocardial oxygen demand. ${ }^{3}$ An addition- 